\title{
Değişik Ortam ve Sistem Parametreleri İçin Sualtı Kablosuz Optik Haberleşme Monte Carlo Kanal Kapasitesinin İncelenmesi
}

\author{
Yiğit MAHMUTOĞLU*1a, Cenk ALBAYRAK ${ }^{2 b}$, Kadir TÜRK ${ }^{3 c}$ \\ ${ }^{1}$ Recep Tayyip Erdoğan Üniversitesi, Mühendislik ve Mimarlık Fakültesi, Elektrik-Elektronik Mühendisliği \\ Bölümü. 53100 Rize/TÜRKIYE \\ yigit.mahmutoglu@erdogan.edu.tr \\ ${ }^{2}$ Karadeniz Teknik Üniversitesi, Of Teknoloji Fakültesi, Elektronik ve Haberleşme Mühendisliği Bölümü. 61080 \\ Trabzon/TÜRKIYE \\ ${ }^{3}$ Karadeniz Teknik Üniversitesi, Mühendislik Fakültesi, Elektrik-Elektronik Mühendisliği Bölümü. 61080 \\ Trabzon/TÜRKIYE \\ Received/Geliş: 17.12 .2020 \\ Accepted/Kabul: 05.03.2021
}

\begin{abstract}
Öz: Okyanuslara olan ilginin gün geçtikçe artması, bu alanda yapılan ve sualtı kablosuz haberleşme sistemlerinin sıklıkla kullanıldığı bilimsel, ticari ve askeri ağırlıklı çalışmaları da artırmaktadır. Literatürde, sualtında kablosuz olarak senkron ve yüksek hızlı veri aktarımı ancak optik sistemlerle yapılabilmektedir. Sualtı ortamının optik dalgalar üzerindeki bozucu etkileri, sualtı kablosuz optik haberleşme (UWOC) sistemlerinin haberleşme mesafesini ve hızını önemli ölçüde etkilemektedir. Bu nedenle, güvenilir UWOC sistemlerinin tasarlanabilmesi için farklı sualtı ortamlarının UWOC sistemleri üzerindeki etkilerinin detaylı bir şekilde incelenmesi ve bu incelemelerin de gerçekçi bir kanal modeli üzerinden yapılması önem arz etmektedir. Bu çalışmada, yaklaşık kanal modelleri yerine, sağladığı yüksek doğruluk ve hassasiyeti ile literatürde kabul görmüş olan Monte Carlo yaklaşımlı UWOC kanal modeli kullanılmış olup, UWOC sistemleri için önemli tasarım parametreleri olan vericinin ışını yayma açısı, alıcının açıklık çapı parametrelerinin tipik bir UWOC sistemi üzerindeki etkileri incelenmiştir. Yapılan incelemelerde, literatürde sıklıkla karşılaştırma amacıyla kullanılan temiz okyanus suyu, kıyı okyanus suyu ve liman suyu olmak üzere üç farklı sualtı ortamı dikkate alınmış olup, her sualtı ortamı için kanal dürtü yanıtları, sinyal gürültü oranı ve kanal kapasitesi dağılımları sunulmuş ve yorumlanmıştır. Elde edilen sonuçlar ile tipik bir UWOC sisteminin haberleşme hızı ve mesafe sınırları belirlenmiş olup, farklı sualtı ortamlarında ve parametre değerlerinde kullanılabilecek UWOC sistemleri için bir öngörü sağlanmıştır.
\end{abstract}

\section{Investigation of Underwater Wireless Optical Communication Monte Carlo Channel Capacity for Various Environments and System Parameters}

\begin{abstract}
Increasing interest in oceans increases the scientific, commercial and military studies in this field, in which underwater wireless communication systems are frequently used. In literature, underwater wireless, synchronous, high speed data transfer can only be done with optical systems. The distorting effects of underwater environment (UE) on optical waves significantly affect the communication distance and speed of underwater wireless optical communication (UWOC) systems. Therefore, in order to design reliable UWOC systems, it is important to examine effects of various UEs on UWOC systems on a realistic channel model. In this study, instead of the approximate channel models, Monte Carlo approach UWOC channel model, which is accepted in literature with its high accuracy and sensitivity, was used, and effects of the transmitter's beam divergence angle and aperture diameter of receiver parameters, which are important design parameters for UWOC systems, on a typical UWOC system were investigated. In this study, three various UEs, namely clean ocean, coastal ocean and harbor waters, which are frequently used as benchmarks in the literature, were taken into consideration, and


channel impulse responses, signal to noise ratios and channel capacity distributions were presented and interpreted for each UE. With the results obtained, the communication speed and distance limits of a typical UWOC system were determined, and a prediction was provided for UWOC systems that can be used in various UEs and parameter values.

Keywords: Underwater wireless optical communication; Monte Carlo approximation; Channel capacity

\section{Giriș}

Dünya yüzeyinin \%70'inden fazlasını kaplayan su kütlesi hala birçok bilinmezi içinde barındırmaktadır. Günümüzde, bu bilinmezleri keşfetmek ve sundukları imkânlardan yararlanmak için okyanus, deniz ve göllerde yoğun şekilde çalışmalar yürütülmektedir. Bu çalışmalar su altında kablosuz haberleşme ihtiyacını da beraberinde getirmektedir [1,2]. Sualtı ortamında kablosuz veri aktarımı için elektromanyetik, akustik ve optik dalgalar kullanılabilmektedir [3].

Elektromanyetik dalgalar (karasal ortamda sıklıkla kullanılmaktadırlar [4,5]) deri etkisinden (skin effect) dolayı, sualtı ortamında çok fazla zayıflamaktadır [6]. Bundan dolayı sualtında elektromanyetik dalgalar kullanılarak Mbps seviyelerinde veri aktarımı sağlanabiliyor olmasına rağmen, haberleşme mesafesi oldukça kısa (en fazla $10 \mathrm{~m}$ ) kalmaktadır [3,7]. Elektromanyetik sistemlerin düşük frekanslarda kullanımı haberleşme mesafesi arttırılabilmektedir, fakat bu durum, oldukça büyük antenlerin ve yüksek güçlü vericilerin, yani yüksek maliyetli sistemlerin kullanımını gerektirmektedir.

Diğer bir alternatif olan akustik haberleşme sistemleri, sualtı kablosuz haberleşmesinde yaygın olarak kullanılmaktadır. Akustik sistemler ile sualtı ortamında yüz kilometrelerce mesafelerde veri aktarımının gerçekleştirilebilmesi mümkün hale gelmektedir [8]. Fakat akustik dalgaların bant genişlikleri oldukça dar olduğundan dolayı, bu sistemler ile ancak düşük hızlı (kbps seviyelerinde) veri aktarımları sağlanabilmektedir [9]. Ayrıca akustik sistemler, yüksek güçlü vericilere ihtiyaç duyan maliyetli ve yüksek gecikmeli sistemlerdir [7, 10].

Sualtı ortamında kablosuz veri aktarımı için kullanılan başka bir alternatif ise optik haberleşme sistemleridir. Optik dalgalar, elektromanyetik dalgalar gibi, sualtı ortamının zayıflatma etkisinden fazlasıyla etkilenmektedir fakat görünür ışık spektrumunun mavi/yeşil bantlarında söz konusu zayıflatma etkisi, spektrumun diğer bölgelerine göre, en aza inmektedir. Bu durum, görünür 1ş1k spektrumunun mavi/yeşil bantlarını kullanan sualtı kablosuz optik haberleşme (UWOC) sistemleriyle sualtında $10 \mathrm{~m}$ ile $100 \mathrm{~m}$ mesafelerde Gbps seviyelerinde veri aktarımının yapılabilmesine olanak sağlamıştır [2, 7, 11-15]. UWOC sistemleri, elektromanyetik ve akustik sistemlere kıyasla daha düşük güç tüketen sistemler olup, sualtı ortamında kısa ve orta menzilde yüksek hızlı veri iletişimi gerektiren uygulamalar için tek alternatif olarak öne çıkmaktadır.

Veri iletişim hızı düşük olan sistemlerin kullanımı, okyanus araştırmalarını sınırlandıran bir husus olmaktadır. Bu anlamda, sualtı ortamında yüksek hızlı veri iletişimi için UWOC sistemleri, yukarıda belirtilen özelliklerinden dolayı önemli bir çözüm olarak endüstri ve akademinin dikkatini çekmektedir. Sualtı ortamının optik dalgalar üzerindeki emilim, saçılma vb. bozucu etkileri, UWOC sistemlerinin haberleşme mesafesi, veri iletişim hızı gibi haberleşme performanslarını önemli ölçüde etkilemekte ve sinırlamaktadır. Güvenilir UWOC sistemlerinin tasarlanabilmesi ve kullanım senaryolarının belirlenebilmesi açılarından farklı sualtı ortamlarının UWOC sistemleri üzerindeki etkilerinin detaylı bir şekilde incelenmesi ve bu incelemelerin de gerçekçi bir kanal modeli üzerinden yapılması önem arz etmektedir. İlgili literatürdeki çoğu çalışmada yapısal basitliklerinden dolayı yaklaşık kanal modelleri (Beer-Lambert) kullanılmaktadır [16-18]. Bundan dolayı da söz konusu çalışmalarda sunulan sonuçlar, bir UWOC sisteminin performans sinırlarını tam olarak söyleyememektedir. Bu çalışmada ise yapılan incelemelerde, yaklaşık kanal modelleri yerine, 
yükssek doğruluk ve hassasiyet sağladığı literatürde kanıtlanmış olan Monte Carlo yaklaşımlı UWOC kanal modeli kullanılmıştır [19-21].

$\mathrm{Bu}$ çalışmada, literatürde karşılaştırma için yaygın olarak kullanılan temiz okyanus suyu (TOS), kıyı okyanus suyu (KOS), liman suyu (LS) ortamlarının ve vericinin ışını yayma açısı, alıcının açıklık çapı gibi önemli tasarım parametrelerinin tipik bir UWOC sistemi üzerindeki etkileri incelenmiştir. Yapılan incelemelerin tamamında Monte Carlo tabanlı UWOC kanal modeli dikkate alınmış olup, her sualtı ortamı için kanal dürtü yanıtları, sinyal gürültü oranı (SNR) ve kanal kapasitesi dağılımları elde edilmiş, sunulmuş ve yorumlanmıştır. Sunulan sonuçlarla, UWOC sistemleri için mevcut limitler ortaya çıkarılmış olup bu konuda çalışanlara çeşitli sualtı ortamları için UWOC sistemleri ile gerçekleştirilebilecek uygulamalar hakkında fikir verebileceği umulmaktadir.

\section{Sualtı Kablosuz Optik Haberleșme Kanalı}

\subsection{Monte Carlo Yaklaşımlı Kanal Modeli}

Kablosuz iletişim sistemlerinde, noktadan noktaya veri iletişiminin yapıldığ senaryolarda genellikle verici ve alıcı birimler arasında direk görüşün (Line of sight, LOS) olduğu varsayılmaktadır. Bu çalışmada da ele alınan LOS senaryosu Şekil 1'de gösterilmekte olup, verici ve alıcı birimler arasında direk görüşü engelleyecek herhangi bir nesnenin olmadığı varsayılmaktadır. Çalışmada ele alınan Monte Carlo tabanlı sualtı kablosuz optik haberleşme kanal modeli aşağıda detaylı olarak açıklanmıştır.

Işığın sualtı ortamındaki yayılımı fazlasıyla karmaşık bir yapıya sahip olduğundan dolayı, sualtı kablosuz optik haberleşme kanal modelinin doğru bir şekilde elde edilmesi oldukça zordur [2]. UWOC kanalı, bir ortamdan geçen ış1k dalgasını enerjinin korunumu kanununa göre tanımlayabilen 1şınım transfer denklemi (Radiative Transfer Equation, RTE) ile tamamen modellenebilmesine rağmen, literatürde RTE'nin kesin bir analitik çözümü bulunmamaktadır [1]. RTE'nin çözümü için yaklaşık analitik çözümler önerilmektedir, fakat, bu çözümler ile yüksek doğruluğa ulaş1lamamaktadır [7, 20]. Bu analitik çözümlere alternatif olarak, istatistiksel verilere dayanarak RTE'nin çözümünün yüksek doğrulukta elde edilebilmesine olanak sağlayan Monte Carlo yaklaşımı, UWOC kanalının modellenmesi için literatürde yaygın olarak kullanılmaktadır [20, 21]. $\mathrm{Bu}$ çalışmada da ele alınan UWOC sisteminin kanal modelini elde etmek için, esnek yapısı, kolay programlanması, hassasiyeti ve doğruluğu yükssek sonuçlar sağlayabilmesinden dolayı Monte Carlo yaklaşımı kullanılmıştır.

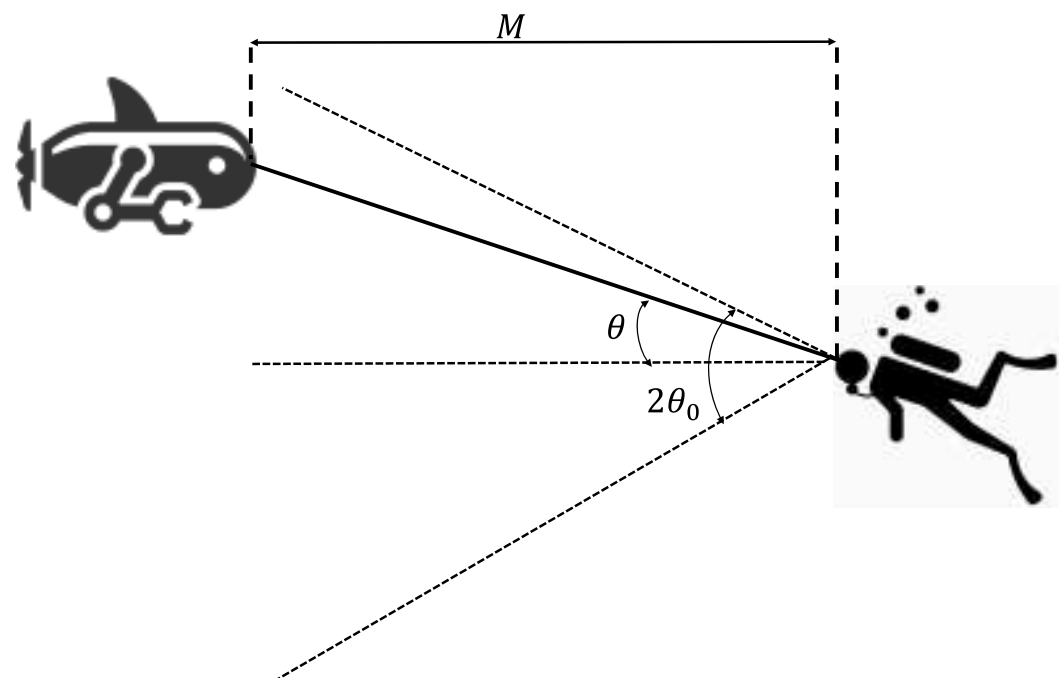

Şekil 1. LOS haberleşme senaryosu 
UWOC kalanının Monte Carlo yaklaşımı ile modellenmesi işleminde, verici birimin özelliklerine bağlı olarak başlangıç hareket yönü değişen çok sayıda foton üretilmekte ve bu fotonların su altı ortamındaki ilerleyişlerinin takibi yapılmaktadır. Takibi yapılan foton sayısının arttırılması, su altı ortamdaki olası bütün durumların hesaba katılmasını sağlayacağından, elde edilen sonuçların doğruluğu ve hassasiyeti artacaktır. Literatürdeki ilgili çalışmalar, $10^{9}$ adet foton ile elde edilen sonuçların yüksek doruluk ve hassasiyeti sağlayabildiğini göstermektedir [21].

Monte Carlo yaklaşımındaki foton takibinin akış şeması Şekil 2'de verilmişsir. Herhangi bir fotonun su altı ortamındaki ilerleyişinin takibi için verilen bu işlem adımları, çok sayıda foton için tekrarlanmaktadır. Söz konusu takip esnasında foton alıcı birim tarafından alınmışsa, fotonun alınma zamanı ve ağırlık (normalize güç) bilgileri kaydedilmektedir. Sonuçta, vericiden gönderilen fotonların zamanın hangi anında hangi güçte alıcı birim tarafından alındığı bilgileri elde edilmiş olup, bu bilgiler üzerinden UWOC kalanın dürtü yanıtı hesaplanabilmektedir.

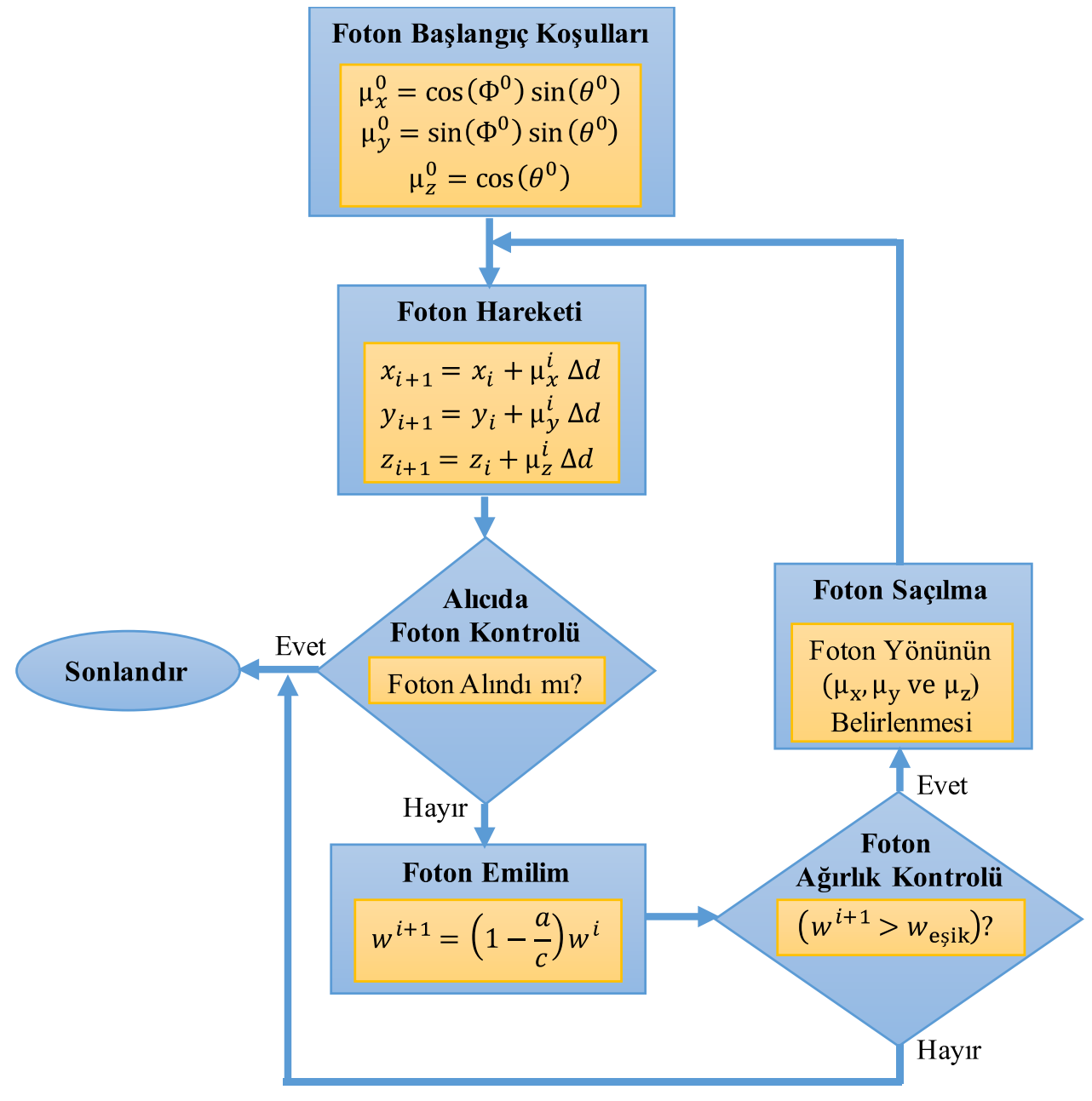

Şekil 2. Monte Carlo tabanlı UWOC kanal modelinin akış şeması

Monte Carlo yaklaşımının ilk adımında, takibi yapılacak her bir fotonun başlangıç koşulları belirlenmektedir. Başlangıç anında her bir fotonun ağırlığı $(w) 1$ ve konumu da vericinin konumuyla aynıdır. Herhangi bir fotonun başlangıç hareket yönü $\left(\mu_{\mathrm{x}}^{0}, \mu_{\mathrm{y}}^{0}, \mu_{\mathrm{z}}^{0}\right)$ ise akış şemasındaki "Foton Başlangıç Koşulları" isimli blokta verilen ve literatürde doğrultu kosinüsü olarak bilinen formüller ile hesaplanmaktadır [22]. Bu formüllerdeki başlangıç açıları $\Phi^{0}$ ve $\theta^{0}$, fotonun başlangıç hareket yönünü belirleyen sırasıyla azimut ve zenit açılarıdır. Bu açı bilgileri (1) ve (2)'de verildiği gibi belirli dağılımlara göre hesaplanmaktadır [22]. Bu denklemlerdeki $R^{\left(\Phi^{0}\right)}$ ve $R^{\left(\theta^{0}\right)}$, sıfır ile bir 
arasında düzgün dağılımlı iki bağımsız rasgele değişkendir. Ayrıca $\theta_{t}$, 1şık kaynağının normalinin x ekseni ile yaptığı açıyı ve $\Phi_{t}$ ise vericinin ışın yayma açısını temsil etmektedir.

$$
\begin{gathered}
\Phi^{0}=2 \pi R^{\left(\Phi^{0}\right)} \\
\theta^{0}=\cos ^{-1}\left(1-R^{\left(\theta^{0}\right)}\left(1-\cos \left(\frac{\Phi_{t}}{2}\right)\right)\right)+\frac{\pi}{2}-\theta_{t}
\end{gathered}
$$

Belirlenen başlangıç yönü doğrultusunda her foton su altı ortamında $\Delta \mathrm{d}$ mesafesi kadar ilerletilir. Bir fotonun ilerletileceği $\Delta \mathrm{d}$ mesafesi, su altı ortamın türüne göre değişen zayıflama katsayısı $c$ 'ye bağlı olarak $\Delta d=-\ln \left(R^{(d)}\right) / c$ şeklinde hesaplanmaktadır [21]. Burada $R^{(d)}$, sıfır ile bir arasında değer alan düzgün dağılımlı rasgele bir değişkendir. Bir fotonun su altı ortamında $\Delta d$ mesafesi kadar ilerledikten sonraki yeni konumu akış şemasındaki "Foton Hareketi" bloğunda verilen denklemler ile hesaplanmaktadır [22]. Bu denklemlerdeki $\left(x_{i}, y_{i}, z_{i}\right)$ fotonun ilerlemeden önceki konumunu belirtirken, $\left(x_{i+1}, y_{i+1}, z_{i+1}\right)$ ise fotonun $\Delta \mathrm{d}$ mesafesi kadar yol aldıktan sonraki konumunu ifade etmektedir. Monte Carlo yaklaşımında bir foton her $\Delta \mathrm{d}$ mesafesi kadar yol aldıktan sonra fotonun, akış şemasındaki "Alıcıda Foton Kontrolü” bloğunda verildiği gibi, alıcı tarafından alınıp alınmadığı kontrol edilir. Bir fotonun alıcı tarafından alınabilmesi için fotonun, alıcı düzlemi olan lens düzlemine, alıcının görüş alanı olan FOV $\left(\Phi_{r}\right)$ açısısın yarısı kadarlık bir açıyla ulaşmış olması gerekmektedir. Başka bir ifadeyle, $\Phi_{f} \leq\left(\Phi_{r} / 2\right)$ şartı sağlanmalıdır. Burada $\Phi_{f}$, fotonun alıcı düzlemine geliş açısıdır. Bu şart sağlanıyorsa, yani foton alıcı tarafından alınmışsa, o foton için zaman ve güç bilgileri kaydedilerek akış şeması sonlandırılır ve yeni bir foton için akış şemasındaki işlemler tekrar başlatılır.

Sualtı ortamında foton ilerleyişini olumsuz yönde etkileyen, emilim ve saçılma olarak bilinen, iki ana etken bulunmaktadır [23]. Emilim, fotonların su molekülü ve su içindeki diğer parçacıklar ile etkileşmesi sonucu termal enerjiye dönüştüğü bir etki iken, saçılma ise fotonların sualtı ortamının molekülleri ve atomları ile etkileşmesi sonucu hareket yönlerinin değişmesidir. Dolayısıyla foton takibi sırasında, fotonlar her $\Delta \mathrm{d}$ mesafesi kadar yol aldıktan sonra alıcı tarafından alınmamışsa emilim ve saçılma etkilerine maruz kalmaktadır. Akış şemasında bu olumsuz etkiler "Foton Emilim" ve "Foton Saçılma" bloklarıyla verilmektedir. Emilim etkisiyle, "Foton Emilim" bloğunda verilen denklemden de anlaşılacağı üzere, toplam ağırlıkları $w^{i}$ olan fotonların bir kısmı su altı ortamında termal enerjiye dönüşmekte iken, ağırlıkları toplamı $w^{i+1}$ değerine azalan geri kalan fotonlar ise ortamda yol almaya devam etmektedir [21]. "Foton Emilim" bloğunda verilen denklemdeki a katsayısı, su altı ortamının emilim katsayısı olup, su altı ortamının türüne göre değişmektedir [21]. Monte Carlo yaklaşımında, emilim etkisinden sonra su altı ortamında yoluna devam edecek fotonların ağırlıkları, akış şemasında "Foton Ağırlık Kontrolü" bloğuyla verildiği gibi, önceden belirlenen bir eşik değerin $\left(w_{\text {eşik }}\right)$ altına inip inmedikleri kontrol edilir. Eşik değerin altında ağırlığı olan fotonların amaçlanan sonuca etkileri ihmal edilecek düzeyde olacağından, takiplerinin yapılmasına gerek duyulmamaktadır [21]. Bu nedenle, eğer foton ağırlığı eşik değerin altında ise o foton alıcı birim tarafından alınmadı kabul edilerek akış şeması sonlandırılmakta ve yeni bir foton için akış şemasındaki işlemler tekrar başlatılmaktadır. Literatürdeki çalışmalarda, $10^{-6}$ eşik değeri ile yüksek doğruluk ve hassasiyette sonuçların elde edilebildiği görülmektedir [21].

$\mathrm{Su}$ altı ortamının emilim etkisinden geri kalan fotonlar, eğer eşik değerin altında değilse, akış şemasında "Foton Saçılma" bloğuyla belirtildiği gibi, su altı ortamının saçılma etkisine maruz kalmaktadır. Saçılma etkisinin sonucunda fotonlar yön değiştir [21, 22] ve yeni yön bilgileri, fotonların yeni azimut $\Phi^{S}$ ve zenit $\theta^{S}$ açıları üzerinden (3)'te verildiği gibi hesaplanır [22, 24]. Saçılma azimut açısı $\Phi^{S}=2 \pi R^{\left(\Phi^{S}\right)}$ şeklinde hesaplanmakta olup, burada $R^{\left(\Phi^{S}\right)}$, sıfır ile bir arasında düzgün dağılımlı rasgele bir değişkendir. Saçılma etkisinin en önemli parametresi ise zenit açısıdır. Saçılma zenit açısı literatürde Henyey-Greenstein (HG) ve iki koşullu HG (TTHG) yaklaşık 
modelleri ile belirlenebilmektedir fakat, bu yaklaşık modeller küçük ve büyük zenit açılarının belirlenmesinde hassas sonuç verememektedirler [21]. Saçılma zenit açısının daha hassas belirlenebilmesi için bu çalışmada, [25] çalışmasında deneysel olarak elde edilmiş olan ve literatürde kabul gören ölçüm değerleri kullanılmıştır.

$$
\begin{aligned}
& \mu_{x}^{i+1}=\frac{\sin \theta^{s}}{\sqrt{1-\left(\mu_{z}^{i}\right)^{2}}}\left(\mu_{x}^{i} \mu_{z}^{i} \cos \Phi^{s}-\mu_{y}^{i} \sin \Phi^{s}\right)+\mu_{x}^{i} \cos \theta^{s} \\
& \mu_{y}^{i+1}=\frac{\sin \theta^{s}}{\sqrt{1-\left(\mu_{z}^{i}\right)^{2}}}\left(\mu_{y}^{i} \mu_{z}^{i} \cos \Phi^{s}-\mu_{x}^{i} \sin \Phi^{s}\right)+\mu_{y}^{i} \cos \theta^{s} \\
& \mu_{z}^{i+1}=-\sin \theta^{s} \cos \Phi^{s} \sqrt{1-\left(\mu_{z}^{i}\right)^{2}}+\mu_{z}^{i} \cos \theta^{s}
\end{aligned}
$$

(3)'teki $\left(\mu_{x}^{i}, \mu_{y}^{i}, \mu_{z}^{i}\right)$ ifadeleri fotonların önceki yönlerini belirtmekte iken, $\left(\mu_{x}^{i+1}, \mu_{y}^{i+1}, \mu_{z}^{i+1}\right)$ ise fotonların su altı ortamının saçılma etkisinden sonraki yönlerini temsil etmektedir. $\left(\left|\mu_{z}^{i}\right|>\right.$ 0.99999 olduğu durumlarda foton yönleri (4)’te verildiği gibi hesaplanır [24].

$$
\begin{aligned}
& \mu_{x}^{i+1}=\cos \left(\Phi^{s}\right) \sin \left(\theta^{s}\right) \\
& \mu_{y}^{i+1}=\sin \left(\Phi^{s}\right) \sin \left(\theta^{s}\right) \\
& \mu_{z}^{i+1}=\frac{\mu_{z}^{i}}{\left|\mu_{z}^{i}\right|} \cos \left(\theta^{s}\right)
\end{aligned}
$$

\subsection{Gürültü}

Ortam 1şığı arka plan gürültüsü, karanlık akım gürültüsü, termal gürültü ve atış gürültüsü bir UWOC sisteminin alıcı birimindeki optik sinyalleri etkileyen ana gürültü kaynaklarıdır [14, 26]. [18] çalışmasına benzer olarak bu çalışmada da kolaylık olması açısından alıcıya ulaşan sinyali etkileyen toplam gürültünün, ortam 1şığı (güneş) arka plan, karanlık akım ve termal gürültü bileşenlerinden oluştuğu göz önüne alınmıştır. Aşağıda verilen gürültü denklemleriyle ilgili tüm değişkenlerin tanımları Tablo 1'de verilmiştir.

Ortam 1şığı arka plan gürültüsünün ana kaynağı, su yüzeyinden yansıyan güneş 1şığıdır. Ortam 1şığ1 arka plan gürültüsünün varyansı, (5)'te verildiği gibi hesaplanabilmektedir.

$$
\sigma_{\text {gün }}^{2}=(1 / 2) q S B \pi D^{2}(F O V)^{2} \Delta \lambda T_{F} E R L_{\text {fak }} e^{(-K h)}
$$

Karanlık akım gürültüsüne, foto-detektörün üstüne 1şık düşmediği durumlarda var olan sabit akım büyüklügü neden olmaktadır. Bu gürültünün varyansı (6)'da verilmiştir.

$$
\sigma_{\mathrm{kr}}^{2}=2 \mathrm{qI}_{\mathrm{kr}} \mathrm{B}
$$

Direnç, sıcaklık ve bant genişliğine bağlı olarak değişen termal gürültünün varsanyı ise (7)'de verildiği gibi hesaplanmaktadır.

$$
\sigma_{\mathrm{tr}}^{2}=\frac{4 \mathrm{kT}_{\mathrm{e}} \mathrm{FB}}{\mathrm{R}_{\mathrm{L}}}
$$

Foto-detektör tarafından alınan sinyali etkileyen toplam gürültünün varyansı, (8)'de verildiği gibi, bütün gürültü bileşenlerinin varyanslarının toplamı şeklinde elde edilmektedir. 


$$
\sigma_{\mathrm{tp}}^{2}=\sigma_{\text {gün }}^{2}+\sigma_{\mathrm{kr}}^{2}+\sigma_{\mathrm{tr}}^{2}
$$

Tek boyutlu (gerçek) bir haberleşme sisteminin kanal kapasitesi, (9)'da (Shannon-Hartley teoremi) verildiği gibi, SNR ve bant genişliğine bağlı olarak hesaplanmaktadır [27].

$$
\mathrm{R}_{\mathrm{b}}=\frac{1}{2} \mathrm{~B} \log _{2}(1+\mathrm{SNR})
$$

Tablo 1. Gürültü formüllerinde kullanılan değişkenler

\begin{tabular}{ll}
\hline Değişken & Tanım \\
\hline $\mathrm{q}$ & Elektronik yük \\
$\mathrm{S}$ & Foto-detektörün hassasiyeti \\
$\mathrm{B}$ & Elektriksel bant genişliği \\
$\mathrm{D}$ & Foto-detektörün açılık çapı \\
$\mathrm{FOV}$ & Sistemin radyan cinsinden görüş alanı \\
$\Delta \lambda$ & Optik filtrenin bant genişliği \\
$\mathrm{T}_{\mathrm{F}}$ & Optik filtrenin geçirgenliği \\
$\mathrm{L}_{\mathrm{fak}}$ & Sudaki yayılımın yöne bağlılığını ifade eden faktör \\
$\mathrm{E}$ & Aşağı yönlü yayılım \\
$\mathrm{K}$ & Zayıflatma katsayısı \\
$\mathrm{R}$ & Aşağı yönlü yayılımın sudaki yansıtıcılığ 1 \\
$\mathrm{~h}$ & Alıcı derinliği \\
$\mathrm{I}_{\mathrm{kr}}$ & Karanlık akım değeri \\
$\mathrm{k}$ & Boltzman sabiti \\
$\mathrm{R}_{\mathrm{L}}$ & Yük direnci \\
$\mathrm{T}_{\mathrm{e}}$ & Kelvin cinsinden sıcaklık \\
$\mathrm{F}$ & Sistemin gürültü faktörü \\
\hline
\end{tabular}

\section{Benzetim Çalışmaları}

$\mathrm{Bu}$ bölümde, mesafe, alıcının açıklık çapı ve 1şının alıcıdan ayrılma açısı parametrelerinin UWOC sistemi üzerindeki etkileri çeşitli su altı ortamları için incelenmiştir. Ele alınan parametrelere bağlı olarak elde edilen kanal kapasitesindeki ve SNR'deki değişimler verilmiş ve yorumlanmıştır. Yapılan çalışmalarda literatürde karşılaştırma amacıyla yaygın olarak kullanılan TOS, KOS ve LS ortamları dikkate alınmıştır. Bu sualtı ortamları için Tablo 2'de verilen emilim $(a(\lambda))$, saçılım $(b(\lambda))$ ve zayıflatma $(\mathrm{c}(\lambda))$ katsayı değerleri kullanılmıştır.

Tablo 2. TOS, KOS ve LS su türleri için a $(\lambda), \mathrm{b}(\lambda)$ ve c $(\lambda)$ 'nın tipik değerleri [25]

\begin{tabular}{llll}
\hline Su türleri & $\mathbf{a}(\boldsymbol{\lambda})\left(\mathbf{m}^{-\mathbf{1}}\right)$ & $\mathbf{b}(\boldsymbol{\lambda})\left(\mathbf{m}^{-\mathbf{1}}\right)$ & $\mathbf{c}(\boldsymbol{\lambda})\left(\mathbf{m}^{-\mathbf{1}}\right)$ \\
\hline TOS (Temiz Okyanus Suyu) & 0.114 & 0.037 & 0.151 \\
KOS (Kiy1 Okyanus Suyu) & 0.179 & 0.219 & 0.398 \\
LS (Liman Suyu) & 0.366 & 1.824 & 2.190 \\
\hline
\end{tabular}

Şekil 1'de gösterildiği üzere, verici ve alıcı birimler (dalgıç ve insansız sualtı aracı) arasında LOS bağlantısının olduğu ve birimlerin UWOC sistemi üzerinden birbirleriyle iletişim kurdukları bir senaryo ele alınmıştır. UWOC sistemi ve verici - alıcı birimleri için parametre değerleri Tablo 3'de verilmiştir. Ayrıca tüm çalışmalarda verici gücünün $1 \mathrm{~W}$ olduğu varsayılmış olup, ele alınan UWOC sisteminin kanalını modellemek için kullanılan Monte Carlo yaklaşımı Tablo 1, 2, 3 ve 4’teki parametreler doğrultusunda uygulanmıştır.

Şekil 3'te, ele alınan UWOC sisteminin Monte Carlo yaklaşımı kullanılarak TOS, KOS ve LS su 
türleri için elde edilmiş kanal dürtü yanıtları verilmiştir. Bu sonuçlar, verici - alıcı arası mesafesinin $15 \mathrm{~m}$, FOV açısının $40^{\circ}$, 1şın ayrılma açısının $\left(\theta_{0}\right) 10^{\circ}$, alıcı açıklık çapının $(D) 50 \mathrm{~cm}$ ve verici alıcı birimlerin tam olarak birbirlerine doğru bakacak şekilde doğrultulduğu durumlar dikkate alınarak hesaplamıştır.

Tablo 3. Benzetim çalışmalarında kullanılan parametre değerleri [14, 26, 28, 29]

\begin{tabular}{ll}
\hline Parametre & Değer \\
\hline Elektriksel bant genişliği $(\mathrm{B})$ & $100 \mathrm{MHz}$ \\
Alıcının açıklık çapı $(D)$ & $1-50 \mathrm{~cm}$ \\
Işın ayrılma açısı $\left(\theta_{0}\right)$ & $1^{\circ}-30^{\circ}$ \\
İletilen ortalama optik güç $\left(\mathrm{P}_{\mathrm{ve}}\right)$ & $1 \mathrm{~W}$ \\
Alıcı derinliği $(h)$ & $30 \mathrm{~m}$ \\
Dalgaboyu $(\lambda)$ & $532 \mathrm{~nm}$ \\
Alıcı düzlemine olan dik ve verici-alıcı iz düşümü arasındaki açı $(\theta)$ & $0^{\circ}$ \\
Görüş alanı (FOV) & $40^{\circ}$ \\
Optik filtrenin bant genişliği $(\Delta \lambda)$ & $10 \mathrm{~nm}$ \\
Alıcının hassasiyeti $(\mathrm{S})$ & $0.35 \mathrm{~A} / \mathrm{W}$ \\
Optik filtrenin geçirgenliği $\left(T_{f}\right)$ & 0.5 \\
Yük direnci ( $\left.\mathrm{R}_{\mathrm{L}}\right)$ & $100 \Omega$ \\
Sistemin gürültü faktörü $(F)$ & 4 \\
Karanlık akım $\left(\mathrm{I}_{\mathrm{kr}}\right)$ & $1.226 \mathrm{nA}$ \\
Aşağı yönlü yayılım $(E)$ & $1440 \mathrm{~W} / \mathrm{m}^{2}$ \\
Aşağı yönlü yayılımın sudaki yansıtıcılığı $(R)$ & $\% 1.25$ \\
Sudaki yayılımın yöne bağlılığını ifade eden faktör $\left(\mathrm{L}_{\mathrm{fac}}\right)$ & $2.9(\mathrm{yatay})$ \\
Sıcaklık $\left(\mathrm{T}_{\mathrm{e}}\right)$ & $290{ }^{\circ} \mathrm{K}$ \\
Boltzman katsayısı $(\mathrm{k})$ & $1.38 \times 10^{-23} \mathrm{~J} / \mathrm{K}$ \\
Elektronik yük $(\mathrm{q})$ & $1.6 \times 10^{-19} \mathrm{C}$ \\
\hline
\end{tabular}

Ayrıca, daha düzgün bir gösterim için kanal dürtü yanıtı eğrileri, fotonların alıcıya ilk ulaştığı zaman başlangıç zamanı kabul edilerek zaman ekseninde kaydırılmıştır. Verilen dürtü yanıtı eğrilerindeki yoğunluk değerleri, belli zaman aralıklarında alıcıya ulaşan fotonların ağırlıkları toplamının, vericiden gönderilen bütün fotonların ağırlıkları toplamına oranlanarak hesaplanmaktadir [21].

Tablo 4. Monte Carlo yaklaşımında kullanılan parametre değerleri

\begin{tabular}{ll}
\hline Parametre & Değer \\
\hline Foton sayısı & $10^{9}$ \\
Foton ağırlık eşik değeri $\left(w_{\text {eşik }}\right)$ & $10^{-6}$ \\
Işı̆̆ın sudaki hızı & $2.25 * 10^{8} \mathrm{~m} / \mathrm{s}$ \\
Işığın sudaki saçılma açısının belirlenmesi için [27] & TOS $\rightarrow$ AUTEC - Test $161-13$ JUL71 - Station 8 \\
çalışmasında kullanılan deneyler & KOS $\rightarrow$ HAOCE -05 AUG71 - Station 11 \\
\hline
\end{tabular}

Elde edilen kanal dürtü yanıtı sonuçlarının literatür ile uyumlu olduğu gözlenmiş olup [21], sualtı ortamının saçılma etkisinden dolayı alıcıya ulaşan fotonların sualtı ortamında izleyeceği yollar farklı olduğundan dolayı, verici ve alıcı arasında direk görüş olsa bile, kanal dürtü tepkilerinin zamanda yayıldığı görülmektedir.

Ele alınan su türleri için Tablo 2'de verilen emilim ve saçılma katsayıları dikkate alındığında emilim ve saçılma etkilerinin en az etkin olduğu su türünün TOS ve en fazla etkin olduğu su türünün ise LS olduğu görülmektedir. 

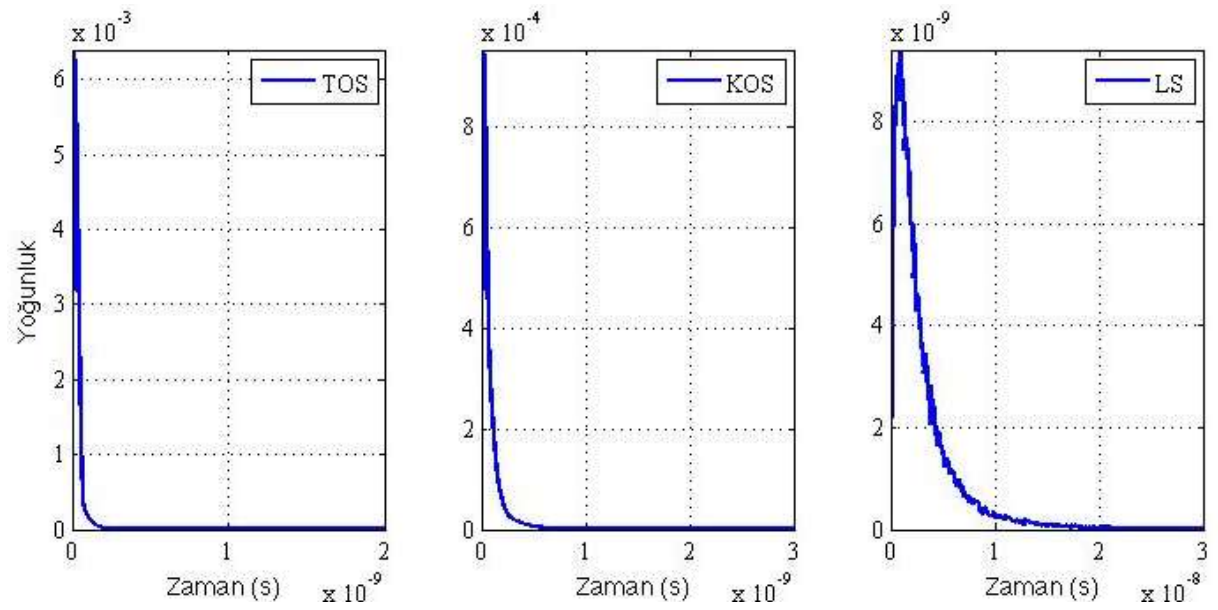

Şekil 3. TOS, KOS ve LS su türleri için Monte Carlo yaklaşımıyla elde edilen kanal dürtü yanıtları

Şekil 3'te verilen kanal dürtü yanıtlarında da emilim ve saçılma bozucu etkilerinin TOS, KOS ve LS su türlerinde beklenen şekilde etkin oldukları sonucuna ulaşılmaktadır. TOS su türünde alıcıya ulaşan fotonların ağırlıkları, diğer su türlerine göre, daha büyük ve zamanda yayılmaları ise daha az (yani emilim ve saçılma etkileri daha az) iken, LS su türünde ise alıcıya ulaşan fotonların ağırlıkları daha küçük ve zamanda yayılmaları ise daha fazla (yani emilim ve saçılma etkileri daha fazla) olmaktadır.

Ele alınan su türlerinin farklı özelliklerinden dolayı neden oldukları farklı emilim ve saçılma etkileri, alıcıdaki SNR'nin büyüklüğünü alıcı birimin konumuna göre değiştirmektedir. Başka bir ifadeyle, verici - alıcı arasındaki mesafe arttığında, emilim daha etkin hale geldiğinden, alıcıdaki SNR azalmakta iken, verici ve alıcı birimlerin birbirlerine göre doğrultuları tam olarak birbirlerine bakacak şekilde olmasa bile saçılma etkisinden dolayı alıcı birimde bir SNR elde edilmektedir. Bahsi geçen bu etkileri daha net gözlemleyebilmek için, Tablo 1, 2, 3 ve 4'te verilen parametreler dikkate alınarak, verici birim olarak kabul edilen 1W'lık 1şık kaynağının TOS, KOS ve LS su altı ortamlarında, alıcı birim olarak kabul edilen foto-detektörde meydana getireceği SNR'nin dağılımı Monte Carlo yaklaşımıla elde edilmiştir. Şekil 4, 5 ve 6'da sırasıyla TOS, KOS ve LS su altı ortamları için elde edilen SNR dağılımları verilmiş olup, verici birimin konumunun sabit ve doğrultusunun $\mathrm{x}$ ekseni doğrultusunda, alıcı birimin ise doğrultusunun -x ekseni doğrultusunda herhangi bir $\mathrm{x}-\mathrm{y}$ konumunda bulunabileceği durumlar dikkate alınmıştır.

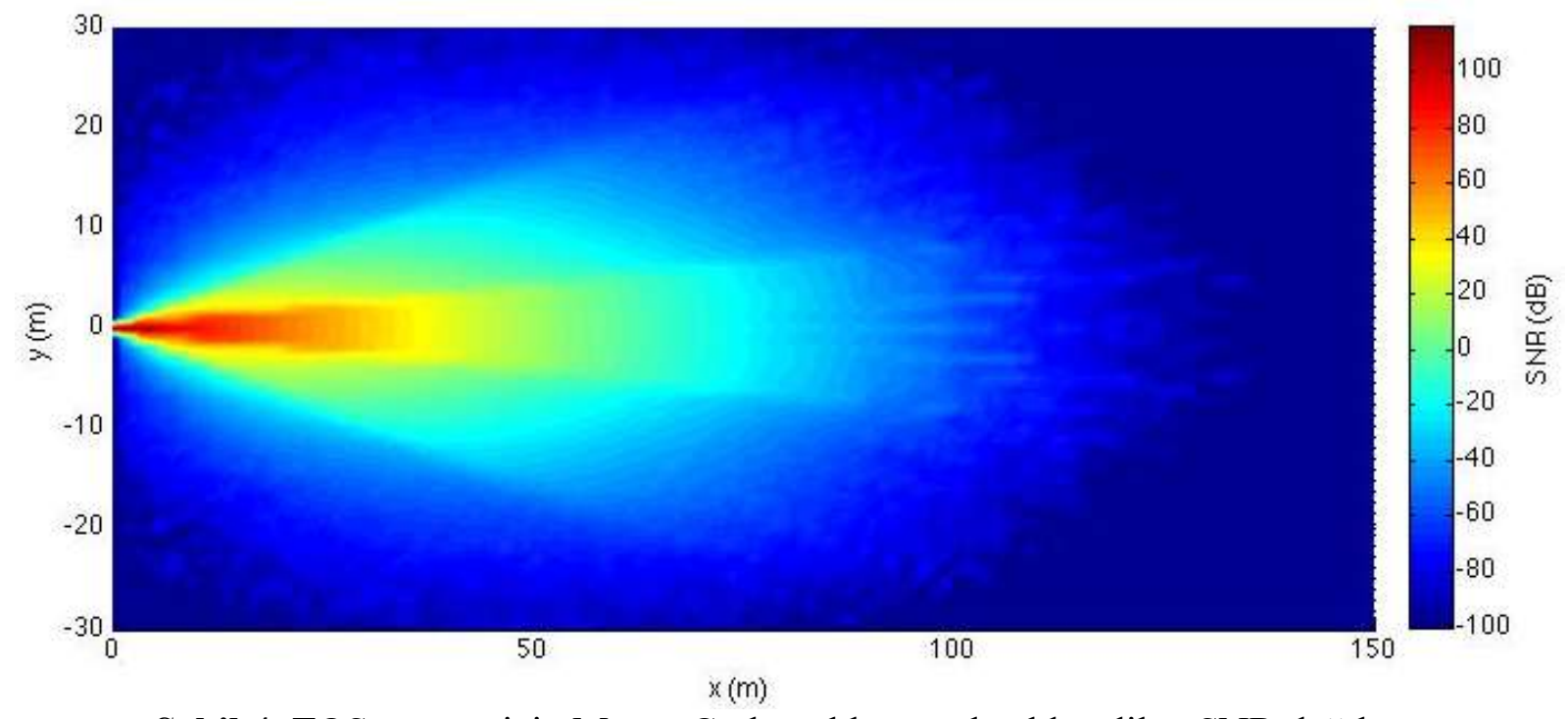

Şekil 4. TOS su türü için Monte Carlo yaklaşımıyla elde edilen SNR dağılımı 


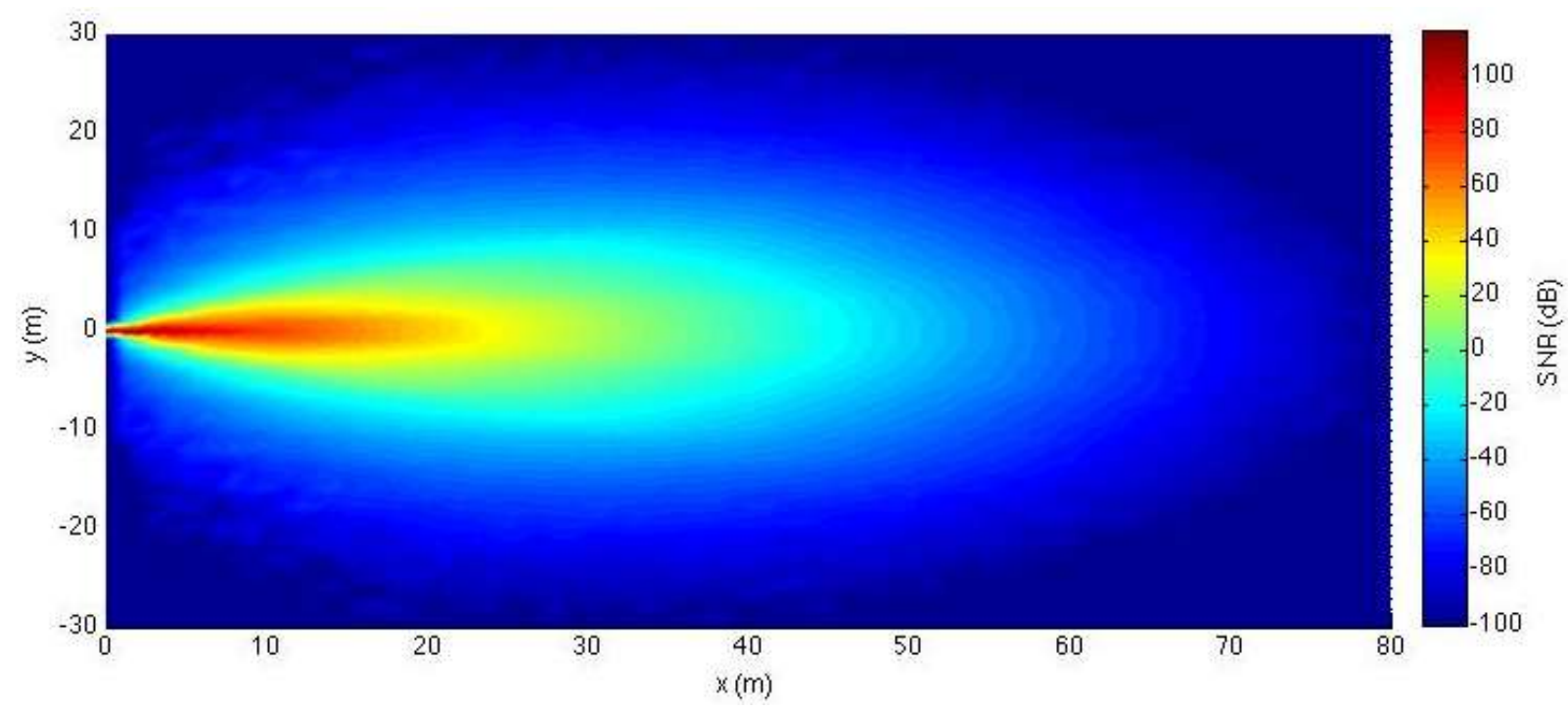

Şekil 5. KOS su türü için Monte Carlo yaklaşımıyla elde edilen SNR dağılımı



Şekil 6. LS su türü için Monte Carlo yaklaşımıyla elde edilen SNR dağılımı

Şekil 4, 5 ve 6'da verilen sonuçlarda, grafiklerin z eksenleri SNR'yi göstermektedir ve her grafiğin sağında bulunan renklendirmeler SNR değerinin büyüklügünü ifade etmektedir. Ayrıca, elde edilen SNR dağılımlarının daha düzgün gösterimi için, $-100 \mathrm{~dB}$ değerinin altındaki SNR değerleri -100 dB olarak değerlendirilerek çizimler yapılmıştır. Aksi taktirde, vericiden çıkan fotonların sualtı ortamında hiç ulaşamadığı konumlarda SNR değerinin $-\infty$ olarak hesaplanma durumları ortaya çıkmaktadır. Sonuçlardan da görüldüğü gibi ele alınan her su türünde, vericiden çıkan fotonlar saçılmakta iken, fotonların ilerleyebileceği mesafe sualtı ortamının emilim etkisinin büyüklügüne göre değişkenlik göstermektedir. Her su türünde, alıcı birim vericiye yaklaştığında alıcıdaki SNR $100 \mathrm{~dB}$ seviyelerine çıkmakta iken, TOS su türü için alıcı birim x ekseni üzerinde 60 metrelerde iken SNR 0dB seviyelerine, yani sinyal gücünün gürültü seviyelerine düşmekte olduğu görülmektedir. Bu durumun, KOS su türü için alıcı birim 30 metrelerde iken, LS su türü içinse alıcı birim 12 metrelerde iken meydana geldiği gözlemlenmiştir. Şekil 7'de KOS su türü için elde edilen kanal kapasitesi dağılımı ve buna göre mesafeye bağlı olarak haberleşme hızının değişimi verilmiş olup, verici birimin konumunun sabit ve doğrultusunun $\mathrm{x}$ ekseni doğrultusunda, alıcı birimin ise doğrultusunun -x ekseni doğrultusunda herhangi bir $\mathrm{x}-\mathrm{y}$ konumunda bulunabileceği durumlar dikkate alınmıştır. 




Şekil 7. KOS su türü için Monte Carlo yaklaşımıyla elde edilen kanal kapasitesi dağılımı

Alıcıdaki SNR ve dolayısıyla kanal kapasitesi verici-alıcı arasındaki mesafeye, 1şının alıcıdan ayrılma açısına ve alıcının açıklık çapına göre değişmektedir. Bahsedilen su ortamları için kanal kapasitesi ve veri iletişim mesafesi arasındaki ilişkiler Şekil 8'de gösterilmiştir. Bu sonuçlar, $5^{\circ}$ lik 1şın ayrılma açısı ve 50 cm'lik alıcı açıklık çapı için elde edilmiştir. Tablo 2'de verilen su altı ortamları için emilim ve saçılma katsayıları dikkate alındığında, bozucu etkilerin baskınlığının TOS, KOS ve LS ortamları sırasıyla arttığı görülmektedir.

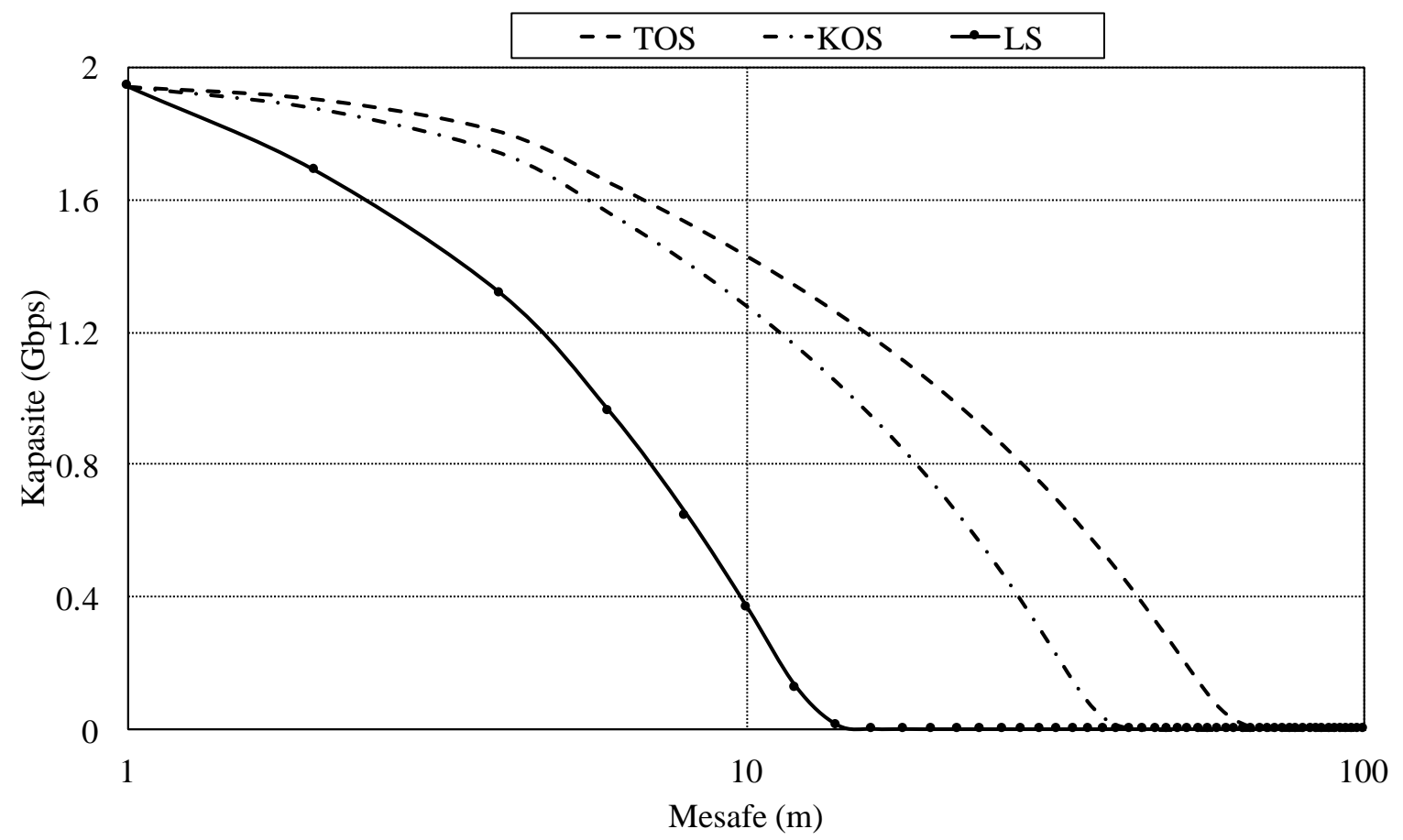

Şekil 8. Farklı sualtı ortamları için kanal kapasitesi ve mesafe arasındaki ilişkiler 
Şekil 8'deki sonuçlar, aynı verici gücü için TOS ve LS ortamlarının sırasıyla en uzun ve en kısa veri iletişim mesafelerine sahip olduğunu göstermiştir. Başka bir ifadeyle, verici ve alıcı arasındaki mesafenin arttırılması alıcıdaki sinyalin gücünü azaltacaktır yani mesafe arttıkça kanal kapasitesi de azalır.

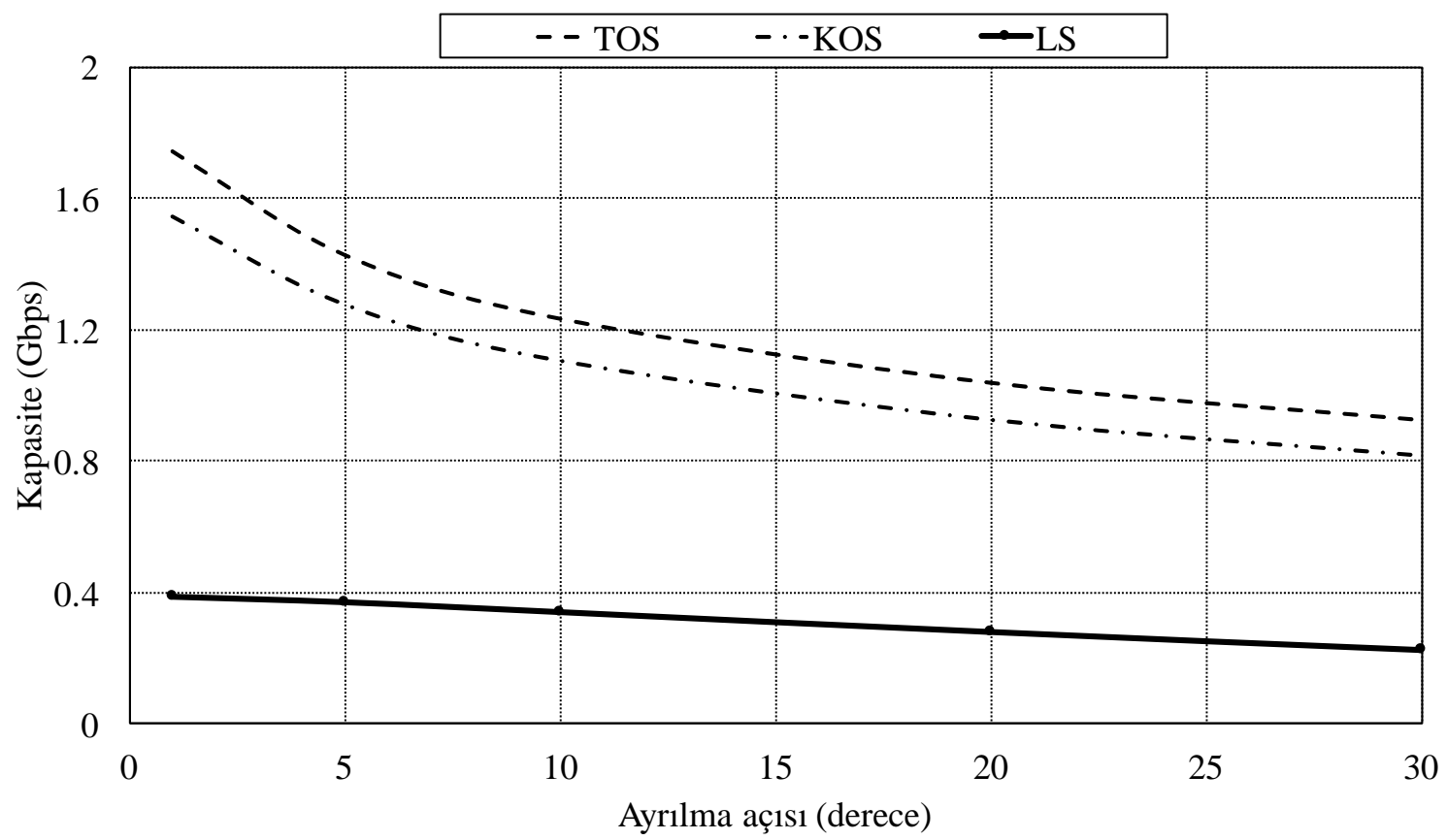

Şekil 9. Farklı sualtı ortamları için kanal kapasitesi ve ışının ayrılma açısı arasındaki ilişkiler

Kullanılan parametrelere göre 10 m'lik haberleşme mesafesi için tüm ortamlarda $>100$ Mbps veri haberleşme hızı seviyelerinde veri iletişimi sağlanabilmektedir ancak TOS ve KOS ortamları için veri haberleşme hızları birbirine oldukça yakın olup LS ortamı için veri haberleşme hızı diğer ortamlara göre 3.9 kat azdır. 100 m'lik haberleşme mesafesinde ise TOS hariç diğer sualtı ortamları için veri iletişiminin mümkün olmadığı görülmektedir.

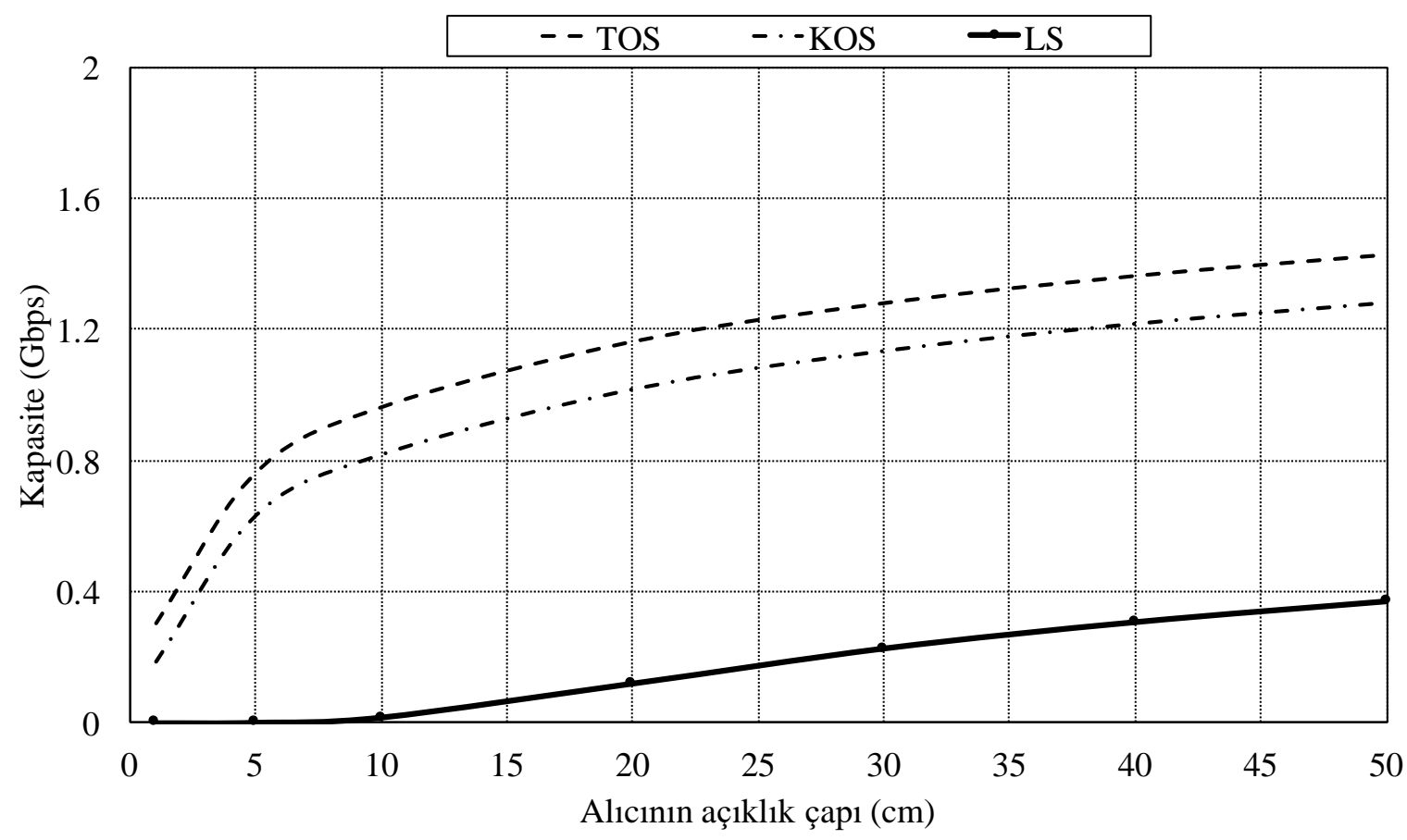

Şekil 10. Farklı sualtı ortamları için kanal kapasitesi ve alıcı açıklı çapı arasındaki ilişkiler 
Verici ve alıcı arasındaki mesafenin $10 \mathrm{~m}$, alıcının açıklık çapının $50 \mathrm{~cm}$ alındığı UWOC sisteminde, kanal kapasitesinin ışın ayrılma açısına göre değişimi Şekil 9'da gösterilmiştir. Burada 1şıının ayrılma açısı $1^{\circ}$ ile $30^{\circ}$ arasında değiştirilmiştir. Şekil 9'da görüldüğü üzere ayrılma açısı arttıkça kanal kapasitesi üstel olarak azalmaktadır. Ayrılma açısı $1^{\circ}$ 'den $30^{\circ}$ 'ye çıkarıldığında veri iletişim hızları TOS ve KOS ortamları için \%53 ve LS ortamı için \%59 oranında azalmıştır. Bu büyük azalma oranlarına rağmen, $30^{\circ}$ 'lik açıda iletişim hızlarının TOS ve KOS ortamları için 1 Gbps seviyesine yakın ve LS ortamı için ise $230 \mathrm{Mbps}$ seviyelerinde olduğu görülmektedir.

Alıcının açıklık çapına göre kanal kapasitelerinin değiş̧imleri Şekil 10'da verilmiştir. Bu incelemelerde, 1 şın ayrılma açısı $5^{\circ}$ ve iletişim mesafesi $10 \mathrm{~m}$ olarak alınmıştır. Alıcının açıklık çapının artırılmasının kanal kapasitesini üstel olarak artırdığg görülmektedir. Alıcının açıklık çapını $1 \mathrm{~cm}$ 'den 50 cm'ye çıkarmak, TOS ve KOS ortamlarında veri iletişim hızlarını sırasıyla 4.7 ve 6.9 kat artırırken, LS ortamında ise 209000 kat artırmıştır. Buradan görüldüğü üzere $50 \mathrm{~cm}$ açıklık için iletişim hızları TOS ve KOS ortamları için 1 Gbps seviyesinin üstündeyken LS ortamı yaklaşı 370 Mbps seviyelerindedir.

\section{Sonuçlar}

Bu çalışmada Monte Carlo yaklaşımıyla elde edilen UWOC kanalı dikkate alınarak sualtı kablosuz optik haberleşme sistemlerinin, verici - alıcı arası mesafeye, ışının vericiden ayrılma açısına ve alıcının açıklık çapına bağlı olarak SNR ve kanal kapasitesindeki değişimleri TOS, KOS ve LS ortamları için incelenmiştir. Ele alınan sualtı ortamları için kanal dürtü yanıtları sunulmuş olup, belli özelliklerdeki verici ve alıcı birimler için, alıcı birimin sualtı ortamındaki farklı konumlarında elde edilen SNR ve kapasite değerlerinin dağılımları gösterilmiştir. Elde edilen sonuçlar farklı sualtı ortamlarının ve tasarım parametrelerinin, UWOC sistemlerinin haberleşme mesafesi ve hızını ciddi ölçüde değiştirdiğini ortaya koymuştur. Bu nedenle, kanal şartlarının sürekli olarak değişkenlik gösterebildiği sualtı ortamlarında, etkin bir biçimde veri iletişiminin sağlanabilmesi için UWOC sistemlerinin geniş bir SNR aralığında çalışacak özellikte tasarlanmaları gerekmektedir.

\section{Yazar(lar)ın Katkıları}

YM, CA ve KT birlikte analiz çalışmalarını yaptı ve makaleyi yazdı. Her üç yazar da makalenin son halini okudu ve onayladi.

\section{Çıkar Çatışması}

Yazarlar, çıkar çatışması olmadığını beyan eder.

\section{Kaynaklar}

[1]. Miramirkhani F., Uysal, M., Visible Light Communication Channel Modeling for Underwater Environments with Blocking and Shadowing, IEEE Access, 2017, 6: 1082-1090.

[2]. Chen H., Chen X., Lu J., Liu X., Shi J., Zheng L., Liu R., Zhou X., Tian P., Toward LongDistance Underwater Wireless Optical Communication Based on A High-Sensitivity Single Photon Avalanche Diode, IEEE Photonics Journal, 2020, 12(3): 7902510.

[3]. Shihada B., Amin O., Bainbridge C., Jardak S., Alkhazragi O., Ng T.K., Ooi B., Berumen M., Alouini M.S., Aqua-Fi: Delivering Internet Underwater Using Wireless Optical Networks, IEEE Communications Magazine, 2020, 58(5): 84-89.

[4]. Gözel M.A, Kasar Ö., Kahriman M., 545 MHz ile 5800 MHz Arası GSM ve ISM Bantlarda, HSMS 285c Diyodu Kullanılarak Yapılan Dickson Doğrultucu Devresinde Tek/Çift Katmanlı Yapının, RF-DC Güç Dönüştürme Verimine Etkisinin İncelenmesi, El-Cezeri Fen ve Mühendislik Dergisi, 2019, 6(1): 24-30. 
[5]. Şentürk A., Karapınar Şentürk Z., Şentürk M., Çiftçi M., Başer E., Yeni Nesil Kablosuz A ̆ Teknolojisi: Wimax Standardının İncelenmesi, El-Cezeri Fen ve Mühendislik Dergisi, 2016, 3(3): 438-447.

[6]. Lin T., Gong C., Luo J., Xu Z., Dynamic Optical Wireless Communication Channel Characterization Through Air-Water Interface, IEEE/CIC International Conference On Communications in China, 2020, Chongqing, China.

[7]. Kaushal H., Kaddoum G., Underwater Optical Wireless Communication, IEEE Access, 2016, 4: 1518-1547.

[8]. Mahmutoglu Y., Hava Taşıtlarının Denizaltı Pasif Akustik Sistemle Uzaktan Algılanma Mesafelerinin İncelenmesi, El-Cezeri Fen ve Mühendislik Dergisi, 2021, 8(1): 133-141.

[9]. Arnon S., Kedar D., Non-Line-of-Sight Underwater Optical Wireless Communication Network, Journal of Optical Society of America A, 2009, 26(3): 530-539.

[10]. Che X., Wells I., Dickers G., Kear P., Gong X., Re-Evaluation of RF Electromagnetic Communication in Underwater Sensor Networks, IEEE Communications Magazin, 2010, 48(12): 143-151.

[11]. Wu T.C., Chi Y.C., Wang H.Y., Blue laser diode enables underwater communication at 12.4Gbps, Scientific Report, 2017, 7: 40480.

[12]. Miller J.K., Morgan K., Li W., Li Y., Johnson E., Data Agile Underwater Optical Communication Link using Flexible Data Formats and Orbital Angular Momentum Multiplexing, OCEANS 2018 MTS/IEEE, 2018, Charleston, SC, USA.

[13]. Cochenour B., Mullen L., Laux A., Spatial and temporal dispersion in high bandwidth underwater laser communication links, IEEE Military Commununications Conference, 2008, San Diego, CA, USA.

[14]. Jaruwatanadilok S., Underwater wireless optical communication channel modeling and performance evaluation using vector radiative transfer theory, IEEE Journal on Selected Areas in Communications, 2008, 26(9): 1620-1627.

[15]. Gabriel C., Khalighi A., Bourennane S., Léon R., Rigaud V., Optical communication system for an underwater wireless sensor network, EGU General Assembly, 2012, Vienna, Austria.

[16]. Ali M., Characteristics of Optical Channel for Underwater Optical Wireless Communication System, IOSR Journal of Electrical and Electronics Engineering, 2015, 10: 1-9.

[17]. Matta G., Agrawal M., Bahl R., Channel Capacity for Underwater Visible Light Communication Systems, Oceans, 2019, Marseille, France.

[18]. Mahmutoglu Y., Albayrak C., Turk K., Investigation of Underwater Optical Communication Channel Capacity for Different Environment and System Parameters, Hittite Journal of Science \& Engineering, 2020, 7(4): 279-285.

[19]. Li J., Ma Y., Zhou Q., Wang H., Channel capacity study of underwater wireless optical communications links based on Monte Carlo simulation, Journal Of Optics A: Pure And Applied Optics, 2012, 14(1): 015403.

[20]. Zeng Z., Fu S., Zhang H., Dong Y., Cheng J., A Survey of Underwater Optical Wireless Communications, IEEE Communications Surveys \& Tutorials, 2017, 19(1): 204-238.

[21]. Tang S., Dong Y., Zhang X., Impulse Response Modeling for Underwater Wireless Optical Communication Links, IEEE Transactions on Communications, 2014, 62(1): 226-234.

[22]. Ding H., Chen G., Majumdar A.K., Sadler B.M., Xu Z., Modeling of Non-Line-of-Sight Ultraviolet Scattering Channels for Communication, IEEE Journal on Selected Areas in Communications, 2009, 27(9): 1535-1544.

[23]. Dong F., Xu L., Jiang D., Zhang T., Monte-Carlo-Based Impulse Response Modeling for Underwater Wireless Optical Communication, Progress in Electromagnetics Research M, 2017, 54: 137-144.

[24]. Cox W.C., Simulation, Modeling, and Design of Underwater Optical Communication Systems, (Doktora Tezi), Department of Electrical Engineering, North Carolina State University, Raleigh, NC, USA, 2012. 
[25]. Petzold, T.J., Volume Scattering Functions for Selected Ocean Waters, Scripps Inst. Oceanogr., La Jolla, CA, USA, Tech. Rep. SIO 7278, 1972.

[26]. Giles J.W., Bankman I.N., Underwater optical communications systems, Part 2: basic design considerations, IEEE Military Communications Conference, 2005, Atlantic City, NJ, USA.

[27]. Sticklus J., Hoeher P.A., Röttgers R., Optical Underwater Communication: The Potential of Using Converted Green LEDs in Coastal Waters, IEEE Journal Of Oceanic Engineering, 2019, 44(2): 535-547.

[28]. Manor H., Arnon S., Performance of an optical wireless communication system as a function of wavelength, Applied Optics, 2003, 42(21): 4285-4294.

[29]. Boucouvalas A.C., Underwater Optical Wireless Communications With Optical Amplification and Spatial Diversity, IEEE Photonics Technology Letters, 2016, 28(22): 26132616. 